\title{
Control Method of STATCOM in Unbalance Voltage Condition
}

\author{
Hao Jing \\ School of North China Electric Power University, Beijing 102206, China \\ jinghao98765@163.com
}

Keywords:STATCOM, Unbalanced System Voltage, current compensation, control strategy.

\begin{abstract}
This paper takes the chain type static synchronous compensator as the research object, introducing the principle of STATCOM, studying control strategy under the unbalanced grid voltage condition. It points out that the imbalance not only makes STATCOM output positive, negative sequence voltage, but also produces three harmonic. This article does decomposition of the current voltage sequence, and does D-Q transformation, to obtain a correct sequence network model, which works well. Through the Mat lab simulation, we prove the correctness and effectiveness of the control strategy.
\end{abstract}

\section{Introduction}

With the continuous development of power systems, the power generation is increasing rapidly. The influence of reactive power has aroused widespread concern. STATCOM has a quick adjusting speed, a wide range of operationand a low harmonic content. Unbalanced grid operation, which is a necessary requirement for most grid connection device. The grid voltage unbalance phenomenon is mainly composed of power system fault and load imbalance. Voltage unbalance operation affection on STATCOM is mainly reflected in two aspects. On the one hand, when the voltage is unbalance, STATCOM inverter DC side voltage on both ends of the capacitor will generate 2 times the fluctuation of the frequency. On the other hand, it will make the device of AC side output voltage and current of negative sequence component and the third harmonic component, which will influence the device output performance.

At present, chain type STATCOM DC side capacitor voltage balancing control strategy mainly adopts the following two methods. The first method is external energy exchanging, which meanly includes DC voltage balance control method based on AC bus energy exchanging and DC voltage balance control method based on DC bus energy exchanging. Through the realization of rectifier and inverter aided circuit, the above two kinds of methods can carry outwithout external control. The other way is accomplished through their own balance algorithm. It uses hierarchical control method. The upper control system is realized in the total active and reactive power control, such as nonlinear control, decoupling control, instantaneous current tracking controland so on.

In sum, so far, research on cascade static synchronous compensator for DC side capacitor voltage balance control is not ideal. Therefore, we should further discuss the unbalanced grid voltage effect on STATCOM operation and design problems of STATCOM device controller, to improve the unbalanced system's reliability, which has the important practical significance.

\section{The establishment of mathematical model of STATCOM}

When the system is asymmetrical, through the symmetrical components method, voltage will be decomposed into positive sequence component, negative sequence component and zero sequence component. Using the unbalance compensation method, we obtain positive, negative sequence component of the load current in the system. We choose negative sequence component of the load current as the current reference. Through the effect of the control ring role, the compensator provides three-phase unbalanced output, to offset the negative sequence current. 


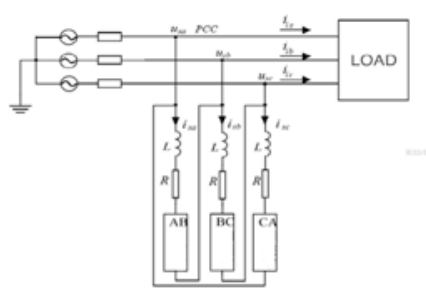

Fig.2-1 STATCOM schematic

Assuming the grid voltage only contains positive and negative sequence component, zero sequence component is removed. Equivalent resistance represents the loss of the whole device. Equivalent inductance $\mathrm{L}$ represents inductance, ignoring the AC side voltage harmonic components of the inverter. Assuming the instantaneous voltage value is:

$\left\{\begin{array}{c}U_{s a}=U_{P} \sin (w t)+U_{N} \sin \left(w t+\delta_{N}\right) \\ U_{s b}=U_{P} \sin \left(w t-\frac{2 \pi}{3}\right)+U_{N} \sin \left(w t+\delta_{N}+\frac{2 \pi}{3}\right) \\ U_{s c}=U_{P} \sin \left(w t+\frac{2 \pi}{3}\right)+U_{N} \sin \left(w t+\delta_{N}-\frac{2 \pi}{3}\right)\end{array}\right.$

Among them: $U_{P}$ is the positive sequence voltage amplitude; $U_{N}$ is the negative sequence voltage amplitude: $\delta_{\mathrm{N}}$ is the phase angle of negative sequence voltage

The current transient model for STATCOM:

$L \frac{d}{d t}\left[\begin{array}{l}i_{c a} \\ i_{c b} \\ i_{c c}\end{array}\right]+R\left[\begin{array}{l}i_{c a} \\ i_{c b} \\ i_{c c}\end{array}\right]=\left[\begin{array}{l}U_{s a} \\ U_{s b} \\ U_{s c}\end{array}\right]-\left[\begin{array}{l}U_{c a} \\ U_{c b} \\ U_{c c}\end{array}\right](2)$

Through decomposition of current voltage sequence, positive and negative sequence components can be independently analyzed as follow;

$$
L \frac{d}{d t}\left[\begin{array}{c}
i_{c c}^{+} \\
i_{c b}^{+} \\
i_{c c}^{+}
\end{array}\right]+R\left[\begin{array}{c}
i_{c a}^{+} \\
i_{c b}^{+} \\
i_{c c}^{+}
\end{array}\right]=\left[\begin{array}{c}
U_{s a}^{+} \\
U_{s b}^{+} \\
U_{s c}^{+}
\end{array}\right]-\left[\begin{array}{c}
U_{c a}^{+} \\
U_{c b}^{+} \\
U_{c c}^{+}
\end{array}\right], \quad \mathrm{L} \frac{\mathrm{d}}{\mathrm{dt}}\left[\begin{array}{c}
\mathrm{i}_{\mathrm{c}}^{-} \\
i_{\mathrm{c}}^{-} \\
\mathrm{i}_{\mathrm{cc}}^{-}
\end{array}\right]+\mathrm{R}\left[\begin{array}{c}
\mathrm{i}_{\mathrm{c}}^{-} \\
\mathrm{i}_{\mathrm{ic}}^{-} \\
\mathrm{i}_{\mathrm{cc}}^{-}
\end{array}\right]=\left[\begin{array}{c}
\mathrm{U}_{\mathrm{sa}}^{-} \\
\mathrm{U}_{\mathrm{sb}}^{-} \\
\mathrm{U}_{\mathrm{sc}}^{-}
\end{array}\right]-\left[\begin{array}{c}
\mathrm{U}_{\mathrm{ca}}^{-} \\
\mathrm{U}_{\mathrm{cb}}^{-} \\
\mathrm{U}_{\mathrm{cc}}^{-}
\end{array}\right](3)
$$

Among them: Superscript + and - respectively express the positive sequence component and negative sequence component.

In the three-phase static coordinate system, STATCOM mathematical model is a set of variable coefficient differential equations. The method bases on D-Q transformation. After transformation, the $\mathrm{ABC}$ coordinate system differential equation with time-varying coefficients converts to synchronous rotating coordinates in the constant coefficient differential equation.Take the transformation matrix as;

$C^{+}=\left[\begin{array}{lll}\sin w t & \sin \left(w t-\frac{2 \pi}{3}\right) & \sin \left(w t+\frac{2 \pi}{3}\right) \\ \cos w t & \cos \left(w t-\frac{2 \pi}{3}\right) & \cos \left(w t+\frac{2 \pi}{3}\right)\end{array}\right], C^{-}=\left[\begin{array}{ccc}-\sin w t & -\sin \left(w t-\frac{2 \pi}{3}\right) & -\sin \left(w t+\frac{2 \pi}{3}\right) \\ \cos w t & \cos \left(w t-\frac{2 \pi}{3}\right) & \cos \left(w t+\frac{2 \pi}{3}\right)\end{array}\right](5)$

After transformation;

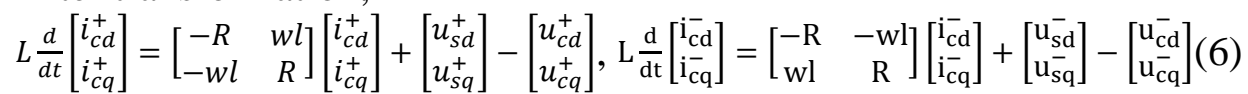

According to the symmetrical component method, the positive and negative sequence components are independent, which can be controlled in the control process separately.

\section{STATCOM control strategyin unbalanced condition}

The first method is to control thechain STATCOM output positive voltage, ignore all kinds of loss. As can be seen from the figure, in this control mode, negative sequence voltage connects directly through the short-circuit reactance, which produces great negative sequence current.

The second approach is to control the STATCOM,at the same time, output the positive sequence and negative sequence voltage. And make the output of the negative sequence voltage and negative sequence voltage of power grid are exactly the same, so they can cancel each other. Only considering the positive sequence fundamental current component. Due to the two-frequency fluctuation of the DC capacitor voltage, through the inverter switching function modulation, STATCOM outputs the positive sequence, negative sequence, and third harmonic voltage component.Therefore, it can't correctly reflect the working statethat thesystem voltage is unbalance. 


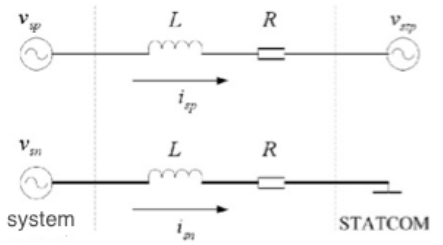

Fig.3-1. The equivalent network when STATCOM only outputs positive sequence voltage

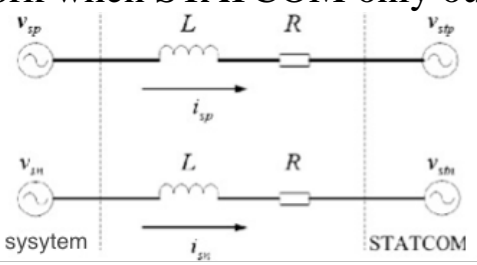

Fig.3-2.The equivalent network when STATCOM only outputs positive sequence voltage

The correct equivalent diagram is shown in Figure 3-3. In order to make the circulation chain capacitor voltage balance, change the exchange flow chain and the system active power, we introduce the negative sequence current control. By adjusting the $\mathrm{i}_{\mathrm{pd}}^{*}$ to change the DC capacitor average voltage, maintain it at the reference value. Through the PI controller, get the output current.

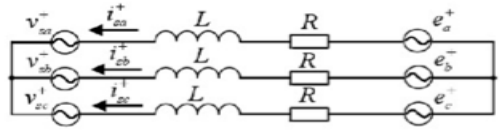

(a) Positive sequence

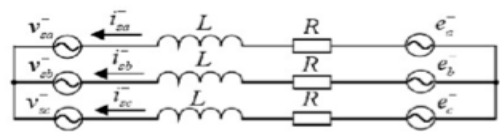

(a) Negative sequence

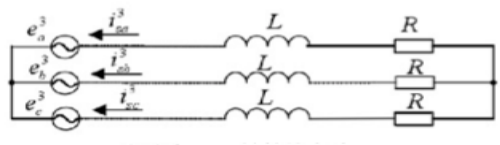

(a) Three harmonic

Fig.3-3. The equivalent network when grid voltage is asymmetrical

\section{Simulation and experiment}

\subsection{The introduction of negative sequence current compensation mode}

When the system voltage has negative sequence component, under the control strategy, the introduction of negative sequence currentchanges the power exchanging. It shows good adaptability in unbalanced grid voltage.

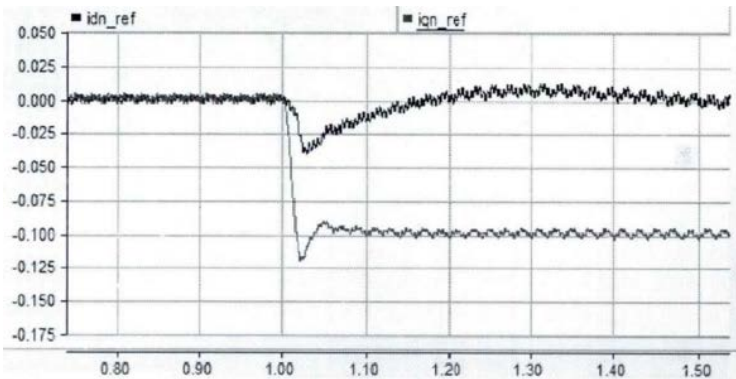

Fig.4-1 Negative sequence current value under the D-Q coordinate 


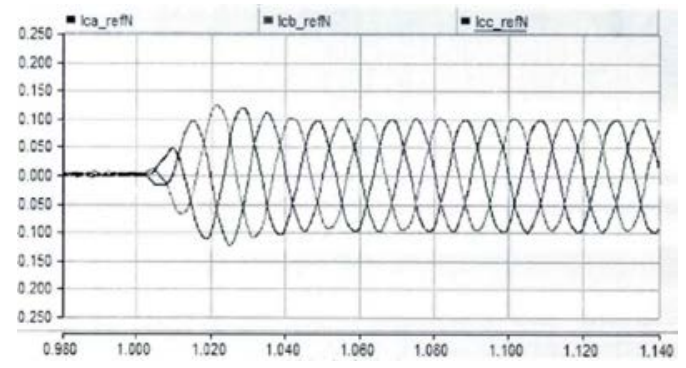

\subsection{Unbalanced load compensation mode}

Fig.4-2 The introduction of negative sequence current

Input three-phase unbalance dinductive load connected triangularly. The current imbalance is obvious. ReplaceSTATCOM DC side capacitor with equal voltage DC power supply. Then input STATCOM to compensate. After STATCOM is put into operation of the power grid, it can compensate the negative and positive sequence component of current. Three-phase balance can be achieved. The grid voltage and current's phaseare exactly the same. Finally achieve unity power factor compensation.

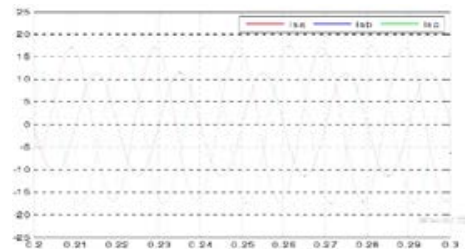

Fig.4-3 Untreated grid current compensation

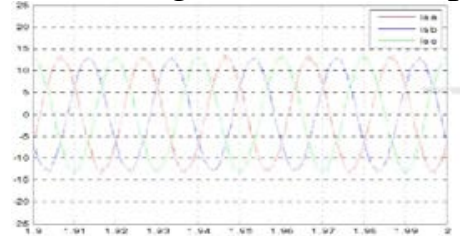

Fig.4-4 Grid current after compensation

\section{Summary}

This paper analyses STATCOM characteristics in voltage unbalance condition. The DC side capacitor voltage waves twice frequency. After the mapping of switching functions, we get the right STATCOM equivalent circuit. In the unbalance current compensation mode, it can realize single power factor compensation. The simulation and experimental results show that the proposed control method can effectively solve the problem of the normal operation of STATCOM in voltage unbalance condition.

\section{Reference}

[1] Zhou Lin, Zhang Youyu, Liu Qiang, et al. Comparative study of three-phase unbalance degree algorithm [J]. East China Electric Power 2010.

[2] LUO An, OU Jianbo, TANG Jie, et al.Research on control method of STATCOM for grid voltage unbalance compensation [J].Proceedings of the CSEE,2009,29(6):55-60.

[3] YUAN Zhichang. The control and protection strategy research on the cascade static synchronous compensator[D]. Beijing:Tsinghua University,2006.

[4] GENG Juncheng, LIU Wenhua, YU Xufeng,et al. Modeling of cascade STATCOM [J]. Procedings of the CSEE,2003, 23(6):65-69.

[5] Barrena, J.A, Marroyo, L., Vidal, M.A.R, Apraiz, J.R.T.. Individual voltage balancing strategy for PWM cascaded H-bridge converter-baced STATCOM[J].IEEE Trans. On Industrial Electronics, 2008, 55(1): 20-29. 
[6] LIU Zhao, LIU Bangyin,DUAN Shanxu,et al. Research on cascade multilevel STATCOM under unbalanced system voltage[J]. Proceedings of the CSEE,2011,31(9):1-7.

[7] YUAN Zhichang. The control and protection strategy research on the cascade static synchronous compensator[D]. Beijing:Tsinghua University,2006. 